Tesis. Año 14, 13(16), 2020, 65-76

\title{
La poesía de Vallejo: Ramón Collar, el Hijo del Hombre
}

\author{
Florencio Luque Rafael \\ florencioluquerafael@gmail.com
}

\section{Resumen}

El objetivo principal de este artículo de investigación es explicar el discurso humanista del poema "VIII Aquí, Ramón Collar", del libro España, aparta de mi este cáliz, de César Vallejo. El humanismo presente es un sincretismo entre dos discursos aparentemente contradictorios por su naturaleza, pero complementarios en sus praxis: de la tradición cristiana, el amor al prójimo; y de la modernidad marxista, el amor al pueblo. Las categorías de interpretación son la retórica y la argumentación. El trabajo concluye en que el amor al prójimo tiene su máxima expresión de humanismo cuando el creyente Ramón dio su vida por los demás, como Jesús lo hizo por nosotros; de la misma forma, el amor al pueblo alcanza la cima del humanismo cuando el combatiente Collar no duda en luchar en la Guerra Civil española defendiendo la causa republicana.

Palabras clave: Ramón Collar, Hijo del Hombre, labrador combatiente, humanismo, César Vallejo.

\section{Abstract}

The main objetive of this research article is to explain the humanist discourse of poem VIII "Here, Ramón Collar", from the book Spain, separates from me this chalice, of César Vallejo. Said humanism is a syncretism between two discourses, apparently contradictory by their nature, but complementary in their praxis: of the Christian tradition, the love to the neighbor, and, of Marxist modernity, love of the people. The categories of interpretation are rhetoric and argumentation. The work concludes that the love of neighbor has its highest expression of humanism when the Ramon believer gave his life for others, as Jesus did for us; in the same way, love for the people reaches the peak of humanism when the combatant Collar does not hesitate to fight in the Spanish Civil War defending the republican cause.

Key words: Ramón Collar, Son of Man, labrador fighter, humanism, César Vallejo 


\section{La poesía de Vallejo: Ramón Collar, el Hijo del Hombre}

\section{Introducción}

Sobre el poema "VIII" Aquí, / Ramón Colar se planteará las siguientes hipótesis. La primera: el humanismo de Vallejo es un sincretismo ${ }^{1}$ entre la tradición cristiana y el marxismo contemporáneo; la segunda, el precepto del amor al prójimo del horizonte cristiano y el amor a las clases desposeídas del horizonte marxista constituyen la base del humanismo vallejiano; y la tercera, son las relaciones dialógicas y la polifonía ${ }^{2}$ entre ambos componentes que configuran el discurso humanista en el texto de César Vallejo.

Para poder explicar dichas hipótesis se utilizará dos paradigmas de interpretación: la retórica que nos permite reconocer un conjunto de metáboles que abordan no solo el dominio lingüístico, sino también el conocimiento del universo ideológico del texto; y la argumentación que se manifiesta en la persuasión y el convencimiento de los discursos planteados.

El presente estudio comprende cuatro partes: primera, la presentación del texto; segunda, la segmentación (a través de versos, estrofas, título y breve explicación); la tercera, el reconocimiento de las metáboles, prosigue la argumentación de los segmentos; y la última, la intertextualidad ${ }^{3}$ entre el texto poético y la Biblia.

\section{Análisis de "Aquí / Ramón Collar"}

Título alternativo: RAMÓN COLLAR ES EL HIJO DEL HOMBRE

El propósito número uno consiste en analizar la condición del labrador $\mathrm{Ra}-$ món Collar y su especial adhesión a la causa de los republicanos. El segundo es argumentar por qué le dicen a Ramón Collar el Hijo del Hombre y, asimismo, se está rezando por él y se pide la bendición del Señor. 


\section{A. Texto $^{4}$}

Aquí,

Ramón Collar,

prosigue tu familia soga a soga,

se sucede,

5 en tanto que visitas, tú, allá, a las siete espadas, en Madrid, en el frente de Madrid.

¡Ramón Collar, yuntero

y soldado hasta yerno de tu suegro,

marido, hijo limítrofe del viejo Hijo del Hombre!

10 Ramón de pena, tú, Collar valiente, paladín de Madrid y por cojones; Ramonete, aquí,

los tuyos piensan mucho en tu peinado!

¡Ansiosos, ágiles de llorar, cuando la lágrima!

15 ¡Y cuando los tambores, andan; hablan

delante de tu buey; cuando la tierra!

¡Ramón! ¡Collar! ¡A ti! Si eres herido, no seas malo en sucumbir; ¡refrénate!

Aquí,

20 Tu cruel capacidad está en cajitas;

aquí,

tu pantalón oscuro, andando el tiempo,

sabe ya andar solísimo, acabarse;

aquí,

25 Ramón, tu suegro, el viejo,

te pierde a cada encuentro con su hija!

¡Te diré que han comido aquí tu carne,

sin saberlo,

tu pecho, sin saberlo,

30 tu pie;

pero cavilan todos en tus pasos coronados de polvo!

¡Han rezado a Dios,

aquí;

se han sentado en tu cama, hablando a voces

35 entre tu soledad y tus cositas;

no sé quién ha tomado tu arado, no sé quién

fue a ti, ni quién volvió de tu caballo!

¡Aquí, Ramón Collar, en fin, tu amigo!

¡Salud, hombre de Dios, mata y escribe! 


\section{B. Segmentación}

\begin{tabular}{|l|l|l|l|l|}
\hline Segmento & Estrofa & Versos & \multicolumn{1}{|c|}{ Título } & \multicolumn{1}{|c|}{ Explicación } \\
\hline 1 & $1-2$ & $1-16$ & $\begin{array}{l}\text { Se siente nos- } \\
\text { talgia por 1a } \\
\text { ausencia del fa- } \\
\text { miliar. }\end{array}$ & $\begin{array}{l}\text { Ramón Collar es el Hijo del } \\
\text { Hombre, el labrador que se va a } \\
\text { pelear en el frente de batalla y deja } \\
\text { un dolor inmenso en la familia. }\end{array}$ \\
\hline 2 & $3-4$ & $17-31$ & $\begin{array}{l}\text { A pesar del } \\
\text { tiempo y la dis- } \\
\text { tancia vives en } \\
\text { nosotros. }\end{array}$ & $\begin{array}{l}\text { El Hijo del Hombre, Ramón Co- } \\
\text { llar, no va a cualquier conflicto } \\
\text { bélico, va a una batalla cuyas cau- } \\
\text { sas son justas; en consecuencia, el } \\
\text { inmenso dolor se acrecienta en la } \\
\text { familia y amigos. }\end{array}$ \\
\hline 3 & $5-6$ & $32-39$ & $\begin{array}{l}\text { Si no regresas, } \\
\text { nunca te olvida- } \\
\text { remos. }\end{array}$ & $\begin{array}{l}\text { Ramón Collar, el Hombre de } \\
\text { Dios, está peleando por los bue- } \\
\text { nos. iCuídate y escríbenos! No- } \\
\text { sotros estamos rezando por ti y } \\
\text { pedimos la bendición del Señor. }\end{array}$ \\
\hline
\end{tabular}

\section{Campo retórico}

El lenguaje literario se enriquece cuando el poeta o el escritor hace uso de un conjunto de recursoscomo las figuras literarias o retóricas; entre las que se cuentan la metáfora, la hipérbole, la rima (consonante o asonante), el ritmo (distribución razonada de los acentos al interior de los versos); también diversas técnicas que provienen de disciplinas como la psicología, el cine, etc. El sentido connotado, por su propia naturaleza, es subjetivo, figurado y permite alcanzar la belleza través de las palabras. Albaladejo (1991) sostiene:

Decisivo para la constitución de la macroestructura del discurso retórico y caracterizador de este en grandísima medida es el ornatus, cualidad de la elocutio que consiste en el embellecimiento del texto retórico en su manifestación textual lineal mediante dispositivos expresivos inherentes a la propia estructura del lenguaje que son actualizados en esta operación con el fin de producir una construcción de nivel de elocutio que atraiga la atención por su elaboración artística, principalmente basada en la exornación lingüística. El hecho de que el ornatus también se dé en el texto literario es, como es sabido, motivo del acercamiento entre elocutio retórica y elocutio literario y es un elemento favorecedor de la caracterización de esta clase de textos artísticos por medio de esta cualidad elocutiva. (p. 128) 
El ornatus del poema se da por el uso del polisíndeton, metábole que se caracteriza por el uso de la conjunción copulativa " $\mathrm{y}$ " en cuatro oportunidades en toda la segunda estrofa (del verso 7 al 16). El yo poético describe al labrador Ramón Collar como un soldado dispuesto a tomar el cielo por asalto. Se resalta su carácter y actitud singulares (etopeya) y su contextura recia y peinado elegante (prosopografía). Es un comunero valeroso que, como todo miliciano, va a la guerra como voluntario y se distingue por sus hazañas. La elocutio es la verbalización de la estructura semántico-intensional del discurso con la finalidad de hacerla comprensible para el alocutario. En el poema se presenta como una sinécdoque (parte/todo) en los versos 22-23: "Tu pantalón oscuro, andando el tiempo, / sabe ya andar solísimo, acabarse;”. O sea, el yuntero Ramón Collar, a pesar que ha muerto en el campo de batalla, sigue viviendo en la comarca que lo vio nacer y en el corazón de sus seres queridos. Esta prosopopeya (otorgar vida a las cosas inertes) se justifica porque los milicianos nunca mueren, solo morirán para siempre si el pueblo no los recuerda. La elocutio se ratifica con la siguiente sinécdoque: "No sé quién ha tomado tu arado, no sé quién / fue a ti, ni quién volvió de tu caballo!" (versos 35-36). Son tres preguntas cargadas de nostalgia que plantea el locutor. Pese a la soledad del campo por la ausencia del combatiente, Ramón Collar continúa arando la tierra, montando en su leal Babieca. La muerte es más dolorosa cuando caen los milicianos, quienes ofrendaron su vida en defensa de la madre republicana.

\section{Argumentación}

- La nostalgia por la ausencia del familiar. Ramón Collar es el hijo del hombre, es el labrador que se va a pelear en el frente de batalla y deja un dolor inmenso en la familia y los amigos.

Ramón Collar es un esforzado labrador que daba de comer, sembraba y cosechaba para el pueblo. Los verbos están en pretérito imperfecto, ya que el campesino ya no vive en la comarca. Él se fue a luchar a otros lugares que necesitaban más ayuda. Sin embargo, dichos verbos también indican tiempo presente, porque la acción de sembrar y cosechar continúan y él sigue viviendo con nosotros. Escobar (1973) plantea:

Lo permanente, lo que continúa, el territorio al cual pertenece Collar es el aquí, según se intuye con claridad desde aquellas series opuestas (...). Son varios los estratos significativos que condensa este sintagma; todos urgentes, afilados, penetrantes: vive por ser hombre de dios, por ser bueno, y por ser revivido y representante para la familia y los amigos. (p. 317)

$\mathrm{Su}$ ausencia deja un gran vacío en la familia y el pueblo, porque no es cualquier persona, es el hijo más querido. Ramón Collar es el yuntero que 
preparaba la tierra con sus rudas manos, abría el surco fraternal, echaba las tiernas semillas, cuidaba el fruto de las malas hierbas y esperaba pacientemente la fiesta de la cosecha. Hoy ya no está presente porque se fue al frente de batalla: "Ramón de pena, tú, Collar valiente, / paladín de Madrid" (versos 10-11). Fuiste el Hijo del Hombre, aquel que luchó y murió por los hombres, eres el comunero fuerte y valeroso, voluntario en la guerra, que se distinguió por sus heroicas hazañas.

- A pesar del tiempo y la distancia vives en nosotros. E1 Hijo del Hombre, Ramón Collar, no va a cualquier conflicto bélico, va a una batalla cuyas causas son justas; en consecuencia, el inmenso dolor se acrecienta en los familiares y amigos.

¿Por qué el miliciano decide partir a la guerra? ¿Cómo se entiende sus ideas y la convicción resuelta?... estas interrogantes y otras más sobre el desarrollo de las ideas políticas tienen que ver con un hecho referencial fundamental como fue la guerra civil española. En cuanto a la ideología y su proceso, Williams (1997) plantea:

a) un sistema de creencias características de un grupo o una clase particular. b) un sistema de creencias ilusorias -ideas falsas o falsa conciencia - que puede ser contrastado con el conocimiento verdadero o científico. c) el proceso general de la producción de significados e ideas. (p. 71).

Cuál es la actitud del yo poético, cómo se da su elección... Ante los conflictos sociales, los implicados enfrentaban una disyuntiva: participar directamente en uno y otro bando u optar por no comprometerse con ninguno de ellos. La tradición popular conserva dichos populares que cuestionan la segunda opción: "quien calla otorga", "el silencio es sinónimo de complicidad"... Este camino, tomado por una parte de la población, se comprende debido a la falta de madurez y conciencia, la cual solo ha traído atraso en un pueblo o país; en cambio, la toma clara de posición ha permitido el progreso y bienestar de los mismos. ¿Cuál fue la actitud tomada por Vallejo? Sin duda, escogió el camino de la acción directa, empuñando la pluma y escribiendo versos reflexivos a favor de la tierna madre ibérica, azotada por el látigo fascista de Franco. Huamán (2014) señala:

Finalmente, en medio de un mundo atónito y callado ante la agresión, contra un pueblo como el español, el poeta César Vallejo elevó su voz no solo para alertar del peligro, sino para cantar más allá de la muerte, la esperanza de un futuro diferente. La batalla de la que nos habla su libro España, aparta de mí este cáliz, no era solamente aquella que se libraba en una tierra ibérica, sino la de todos los días del hombre frente 
a la injusticia y el poder. El poeta, y su España cayeron, pero en las páginas de sus libros, en los oídos de sus lectores y en los millones de jóvenes del mundo, las huestes de voluntarios por la vida siguen marchando y cantando, seguros de su inevitable triunfo. (p. 83)

A pesar del tiempo transcurrido y la distancia lejana, Ramón Collar vive en el corazón de su pueblo. Cuando los colonos miren en las fértiles tierras el tesón de los bueyes, se acordarán del esforzado yuntero Collar; cuando los agricultores vean los agradables frutos, se acordarán de la alegría de Collar. El miliciano del campo sigue viviendo en la flora y fauna, es el eterno labrador de la tierra prometida en donde todos comerán el pan de cada día con el sudor de sus frentes.

- Si no regresas, nunca te olvidaremos. Ramón Collar, el Hombre de Dios, está peleando por los buenos: ¡cuídate y escríbenos!, nosotros estamos rezando por ti y pedimos la bendición del Señor.

En la historia de los artistas en general, y de los poetas en particular, han sido pocos los autores que han tenido la genialidad de haber incursionado en diversos géneros: poesía, novela, cuento, teatro, ensayo, periodismo, crítica literaria, y también tocado una variedad de temas, que incluyen las filias y fobias del ser humano. Uno de ellos es César Vallejo, quien, además de lo señalado, supo armonizar dos discursos: el cristianismo y el marxismo a través del amor al prójimo y la solidaridad con los que más sufren respectivamente. González (2009) plantea:

Con especial énfasis hemos insistido en que Vallejo no es solo un gran poeta del dolor, la muerte, la angustia, la orfandad, el pesimismo, el fatalismo y otras experiencias negativas, tanáticas, sino, y sobre todo, un extraordinario cantor de la vida, el amor, la solidaridad, la esperanza y formidables experiencias positivas, eróticas, teñidas de vuelo profético y evangélico, apocalíptico y revolucionario. (p. 133)

Es interesante la última idea: el vuelo evangélico y revolucionario se constituye como una dualidad necesaria e indispensable en el personaje Ramón Collar. Esto debido a que en el campo de España y otras partes del mundo se ha difundido la historia de la vida, doctrina y milagros de Jesucristo (léase el Evangelio); pero también en ciertos momentos ha habido cambios profundos en las estructuras políticas y socioeconómicas de una nación (léase la revolución socialista). El miliciano Ramón Collar, el "hombre de Dios" (verso 39), se fue a pelear por los buenos y ya no pudo regresar — como Jesús, dio su vida—, mas nunca será olvidado, ya que los pueblos y las naciones siempre tienen sus héroes y santos, a quienes se les recuerda eternamente. 


\section{E. Intertextualidad}

Cuando el yo literario habla de Dios, lo hace para humanizar a los hombres porque hay algunos que atentan — aunque puede resultar paradójico- contra la mayoría de las personas a través de las guerras que organizan, las que expresan intereses económicos, políticos y sociales. En el verso 32: “iHan rezado a Dios," es una crítica a la hipocresía de esos sectores nacionalistas que se dicen cristianos, van a misa, se persignan, pero cometen atrocidades. Lo humano de Dios está en la práctica diaria de amor al prójimo, una solidaridad constante con los más pobres. Al respecto, el padre Gutiérrez (1993), uno de los representantes de la teología de la liberación, ${ }^{5}$ señala:

Deseo precisar que al hablar de dimensión religiosa asumo que su núcleo central es la referencia de un modo u otro a Dios. Hay temas que podemos llamar cristianos, por lo menos en nuestro contexto cultural: caridad, esperanza palabras como fe, incluso fraternidad. (pp. 92-93)

Al interior de la Iglesia cristiana han existido (y actualmente existen) tendencias tanto conservadoras como progresistas. El clero español tomó partido por los sectores nacionalistas; en cambio, parte del pueblo creyente apoyó a los grupos republicanos. En el verso 9, el yo poético dice: "Hijo limítrofe del viejo Hijo del Hombre”. Aquí se refiere al miliciano Ramón Collar, quien se va para luchar por la patria mancillada, sacrificado hijo que lleva su inseparable cruz. En el texto bíblico, la expresión "Hijo del Hombre" se repite muchas veces.

El conocimiento de la naturaleza, la sociedad y el pensamiento es una herramienta para poder lograr una mejor vida; y en el proceso de conseguirlo surgen problemas, inquietudes y preguntas que las diferentes filosofías enfrentan. Es natural en Vallejo su preocupación por el estudio del marxismo, pero también es comprensible su formación cristiana desde niño, como en la mayoría de personas. González (2009) señala al respecto:

Vallejo asumió el marxismo como una vía para la liberación del hombre, como senda de justicia y construcción de un Mundo Nuevo; no como la solución de todos los enigmas e inquietudes. Hasta el final de sus días prestó atención a la complejidad psíquica del hombre, al enigma del Más Allá, en fin, a las cuestiones religiosas y metafísicas. En un apunte del 7 de noviembre de 1937 (en un carnet publicado al final de Contra el secreto profesional) Vallejo abordó la esperanza cristiana en otra vida. Y el 29 de marzo de 1938, enfermo ya de gravedad, dictó a modo de último mensaje, estas palabras a su esposa Georgette: "Cualquiera que sea la causa que tenga que defender ante Dios más allá de la muerte, tengo un defensor: Dios". (p. 12) 
Esta última cita de Geeorgette, compañera y esposa de Vallejo, ha generado polémica en torno a su autenticidad. Suponiendo que Vallejo la hubiera dicho, sería pertinente aclarar, a la luz de su obra y vida, sus grandes temas y dejar así de lado algunos criterios intolerantes o dogmáticos que perjudican el entendimiento del vate santiaguino. Para Vallejo, Dios es amor al prójimo, sobre todo al más pobre, al "pobre pobre" ("Traspié entre dos estrellas").Y ¿quién es el más pobre?: el que no tiene trabajo, y si lo tiene, su sueldo es el mísero básico, que no le da acceso a una buena alimentación, educación, salud. Es decir, es el pueblo y las clases medias, que siempre han estado desposeídas en casi todos los países del mundo. Vallejo no solo habló por los que tienen menos, sino luchó indesmayablemente por ellos, por eso tiene la protección y bendición del Supremo Hacedor.

Silva-Santisteban (2016) señala la importancia del texto bíblico en una serie de versos del poeta. En ellos se pone en primer plano la conciencia, es decir, el conocimiento del bien y del mal, que le permite a la persona enjuiciar moralmente la realidad y los actos, sobre todo, los propios:

Aunque Vallejo utiliza en su poema muchas imágenes como las ya citadas también usa otras como la de la triple negación de Pedro (XIV), la huida a Egipto (II), las referencias al Monte de los Olivos (II), la del Hijo del Hombre (VIII), la de los apóstoles (IV), la de la cruz (XV), etc.: pero el poeta trabaja más en el plano auditivo que en el visual al retomar frases bíblicas o de tipo religioso que se encuentran en todas las conciencias de formación cristiana. (p, 117-118)

El verso "huyendo a Egipto" del poema "II. Batallas" dialoga con la Biblia (Mateo 2: 13-15). El hombre de Extremadura y Málaga, en general el miliciano, no huye a la "tierra prometida" (aunque muchos escapan, porque no quieren tener problemas); sino lucha por ella, no importándole la diáspora y la represión política del franquismo; en el verso "la del hijo del hombre", del poema V "Aquí / Ramón Collar", este es el digno yuntero, el Mesías (Mateo 63: 64), el "hombre de Dios", quien entrega su vida como una ofrenda que la historia escribirá eternamente; "la de la cruz" que "está madre y maestra, cruz y madera" se encuentra en el poema "XV. España, aparta de mí este cáliz"; en el texto bíblico (Hechos 10: 39), la madre llamada España está sangrando por todos sus poros, esta corajuda madre, que enseña a sus hijos a pelear, sigue sufriendo por sus retoños, crucificados como Jesús en el madero de Gólgota. Los milicianos, como Jesús, murieron heroicamente por nosotros; y ¿cuál fue su "pecado"?... el amor a la Humanidad. 


\section{Conclusiones}

- Ramón Collar es un miliciano, llamado el Hijo de Dios, que se va a pelear y deja una profunda nostalgia. Él era un humilde labrador que se ganaba la vida sembrando, con sus rudas manos, las semillas fructíferas; y, como modesto campesino, se identificó con los republicanos y se opuso a los nacionalistas.

- El labrador Ramón Collar no va a cualquier batalla, participa en una guerra histórica; y su ausencia produce un inmenso dolor. Después de que las personas fallecen, muchas son olvidadas porque no dejaron nada bueno para la humanidad; en cambio, pocos serán recordadas, ya que dejaron su valioso aporte para el progreso de un pueblo o país.

- La altísima convicción de Ramón Collar determinó su entrega al ideal; asimismo, el yo poético también planteaba que era un creyente muy sensible ante las injusticias que había en la sociedad. Por eso siempre se le recordará como héroe y santo.

- Los milicianos, como Ramón Collar, no dudaron en ningún momento dar sus vidas en defensa de la patria republicana, como Jesús que también dio su vida por salvar a la humanidad. Por eso Ramón Collar, conocido como "el Hijo del Hombre”, recibe la protección y bendición del Señor y su trascendencia sigue vigente en España y el mundo.

\section{Notas}

1 La categoría de sincretismo permite fusionar dos discursos opuestos como el cristianismo y el marxismo; pero equivalentes en sus praxis humanista y social. El DLE sobre el sincretismo dice: "Sistema filosófico que trata de conciliar doctrinas diferentes" (2001, p. 1405). Este modelo de interpretación no anula cada postura, sino la enriquece, pero en un nivel superior, porque en todo texto coexisten diversas voces (polifonía).

2 No hay texto exclusivamente monofónico; muy por el contario los textos tienden a ser básicamente polifónicos. Precisamente, al respecto Bajtin precisa: "La pluralidad de voces y conciencias independientes e inconfundibles, la auténtica polifonía de voces autónomas, viene a ser, en efecto, la característica principal de las novelas de Dostoievski” (1986, p. 16). Algunos estudiosos proponen diversas categorías de análisis textual: transculturación (A. Rama), heterogeneidad (A. Cornejo Polar), hibridismo cultural (García Canclini), Pachacuti (Mauro Mamani).

3 Sobre la intertextualidad — otra herramienta teórica utilizada en la investigación - es una categoría nueva que ha sido desarrollada por Gerard Genette (1989), quien habla de cinco categorías de interpretación: intertextualidad, paratexto, metatextualidad, hipertextualidad y architexto. El autor de Palimpsestos dice: "Por mi parte la intertextualidad, de manera restrictiva, como una relación de copresencia entre dos o más textos, es decir, eidéticamente y frecuentemente, como la presencia efectiva de un texto en otro" (p. 10). Estas categorías de análisis están presentes en todos los discursos textuales. Por ejemplo, La Eneida es hipertexto cuyo hipotecto es La Odisea; de la misma forma, España, aparta de mí este cáliz es un hipertexto cuyo hipotexto es la Biblia. 
$4 \mathrm{El}$ poema no tiene título. En la parte superior, tres cruces en posición triangular y, a su derecha, a mano: VIII. Cf. Poemas completos (2011, p. 451).

5 La teología de la liberación es una corriente teológica cristiana integrada por varias vertientes católicas y protestantes, nacida en América Latina que se caracteriza por considerar que el Evangelio exige la opción preferencial por los pobres; además, recurre a las ciencias sociales en su interpretación y praxis. El sacerdote peruano Gustavo Gutiérrez es uno de los representantes más conocidos.

\section{Referencias bibliográficas}

Albaladejo, T. (2016). Retórica. Madrid: Editorial Síntesis.

Bajtin, M. (1986). Problemas de la poética de Dostoievski. México: Fondo de Cultura Económica. Título original Problemy poetiki dostoievskogo. Traducción de Tatiana Bubnova.

Escobar, A. (1973). Cómo leer a Vallejo. Lima: P. L. Villanueva Editor.

Genette, G. (1989). Palimpsestos. La literatura en segundo grado. Madrid: Taurus, Alfaguara, S.A. Traducción de Celia Fernández Prieto.

Gonzáles Vigil, R. (2009). Claves para leer a César Vallejo. Lima: Editorial San Marcos E.T.R. L.

Huamán Villaviciencio, M. A. (2014). Vallejo dice hoy... Cómo leer poesía: una aproximación metodológica. Lima: Editorial Cátedra Vallejo.

Perelman, Ch. (1997). El imperio retórico. Retórica y argumentación. Bogotá-Colombia: Editorial Norma.

Raymond, W. (1997). Marxismo y literatura. Barcelona-España:Impreso en Márquez S.A. La edición original inglesa fue publicada bajo el título de Marxism and Literature, por Oxford University. Traducción de Pablo Di Masso.

Real Academia Española (2001). Diccionario de la lengua española. Vigésima segunda Edición. Madrid: Editorial Espasa.

Rowe W. y Gutiérrez. G. (2010). Vallejo, el acto y la palabra. Lima: Fondo Editorial del Congreso del Perú.

Silva-Santisteban, R. (2016). César Vallejo y su creación literaria. Lima: Editorial Cátedra Vallejo.

VV. AA. (1995). Biblia latinoamericana. Edición 105. España: Editorial Verbo Divino.

Vallejo, C. (2011). Poemas completos. Lima: Fondo Editorial UCH. 